SUPPORTING INFORMATION

\title{
Functionalized celluloses with regular substitution pattern by glycosynthase-catalyzed polymerization
}

\author{
Victoria Codera ${ }^{\dagger}$, Kevin J. Edgar ${ }^{*}$, Magda Faijes ${ }^{\dagger}$, Antoni Planas ${ }^{*}{ }^{\dagger}$
}

\begin{abstract}
† Laboratory of Biochemistry, Institut Químic de Sarrià, Universitat Ramon Llull, Via Augusta 390, 08017 Barcelona, Spain and ${ }^{\star}$ Department of Sustainable Biomaterials, Macromolecules and Interfaces Institute, and Institute for Critical Technologies and Applied Science, Virginia Tech, Blacksburg, Virginia 24061, USA.
\end{abstract}

Figure S1. MALDI-TOF spectra of A) synthetic cellulose (5), B) 6-azido 6-deoxycellulose (6), C) acetylated 6-azido 6-deoxycellulose (7).
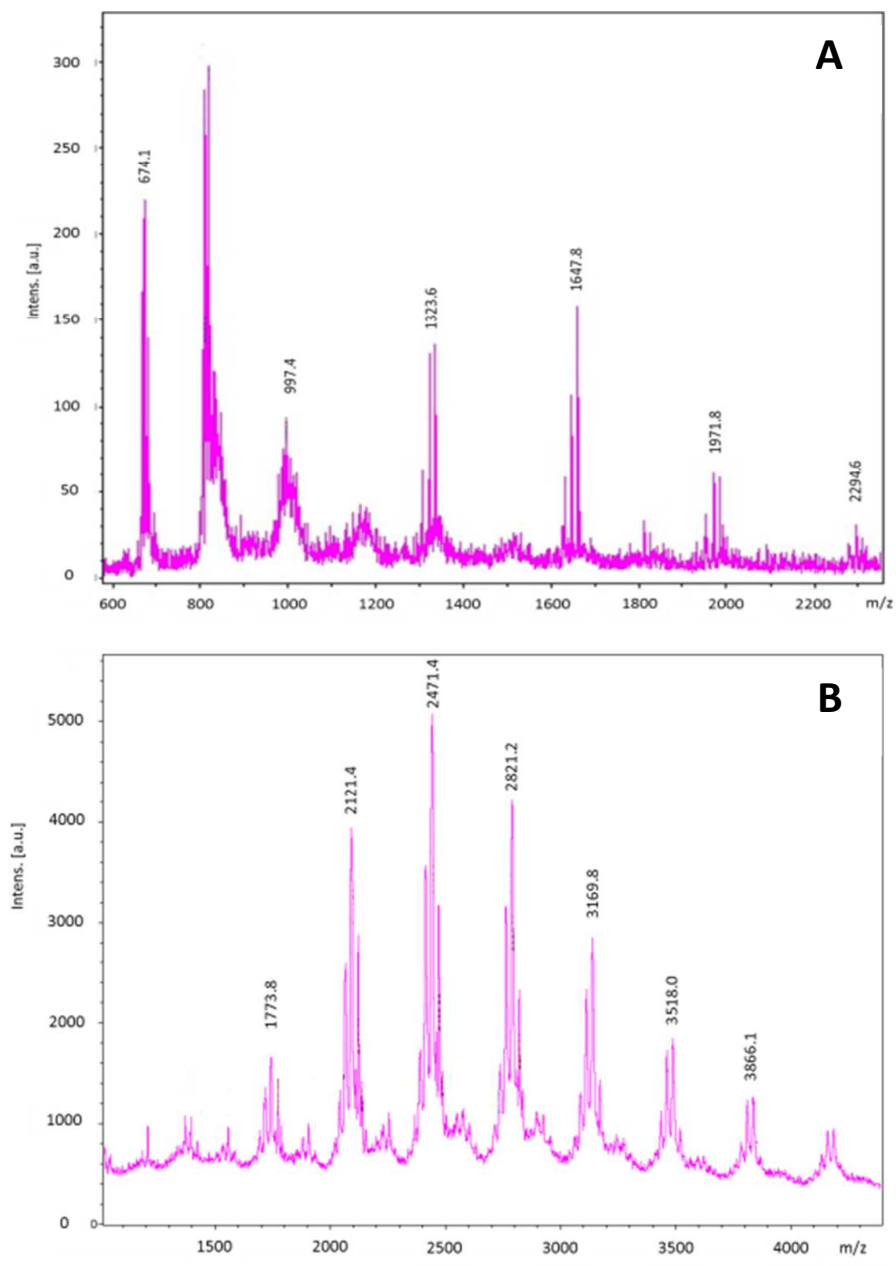


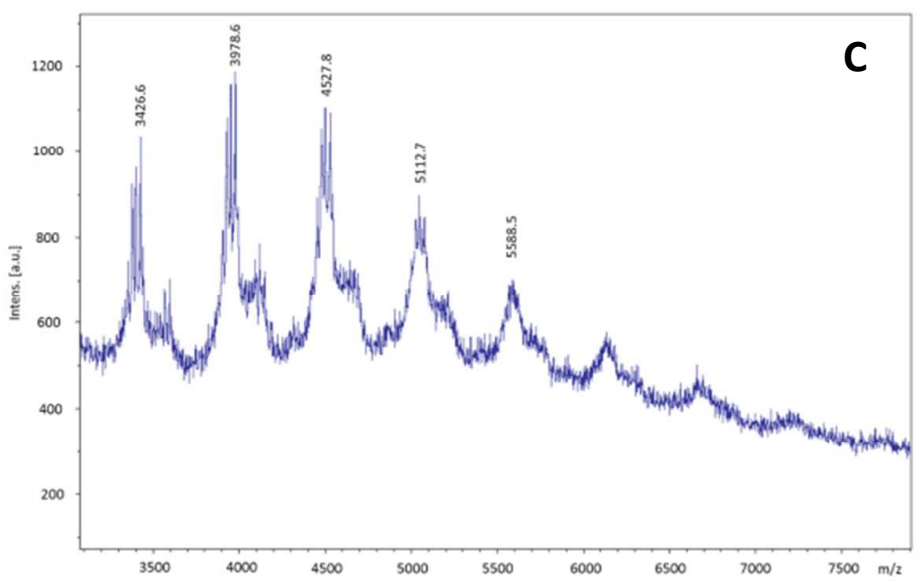

\section{Structure determination of acetylated alternating 6-azido-6-deoxycellulose (7) by NMR}

Due to the presence of the azide at C- $6^{\prime}$ of the cellobiosyl unit, there are two different spin systems and the 6'-azido-glucosyl unit can be distinguished from the glucosyl unit. Bidimensional COSY, TOCSY, and HSQC spectra (Figure S2) allowed the assignment of most ${ }^{1} \mathrm{H}$ and ${ }^{13} \mathrm{C}$ chemical shifts of the acetylated alternating 6-azido-6-deoxycellulose (Figures S3 and S4). The ${ }^{13} \mathrm{C}$ NMR and ${ }^{1} \mathrm{H}-\mathrm{NMR}$ spectra make clear that the proposed two spin systems are present; distinct $\mathrm{C} 1, \mathrm{C} 4, \mathrm{C} 5$, and $\mathrm{C} 6$ carbon signals, and $\mathrm{H} 1, \mathrm{H} 4, \mathrm{H} 5$, and $\mathrm{H} 6$ signals are seen for each spin system but signals corresponding to $\mathrm{C} / \mathrm{H}-2, \mathrm{C} / \mathrm{H}-2^{\prime}$ and $\mathrm{C} / \mathrm{H}-3, \mathrm{C} / \mathrm{H}-3^{\prime}$ are not resolved. 
Figure S2. 2D NMR experiments of acetylated alternating 6-azido-6-deoxycellulose (7).

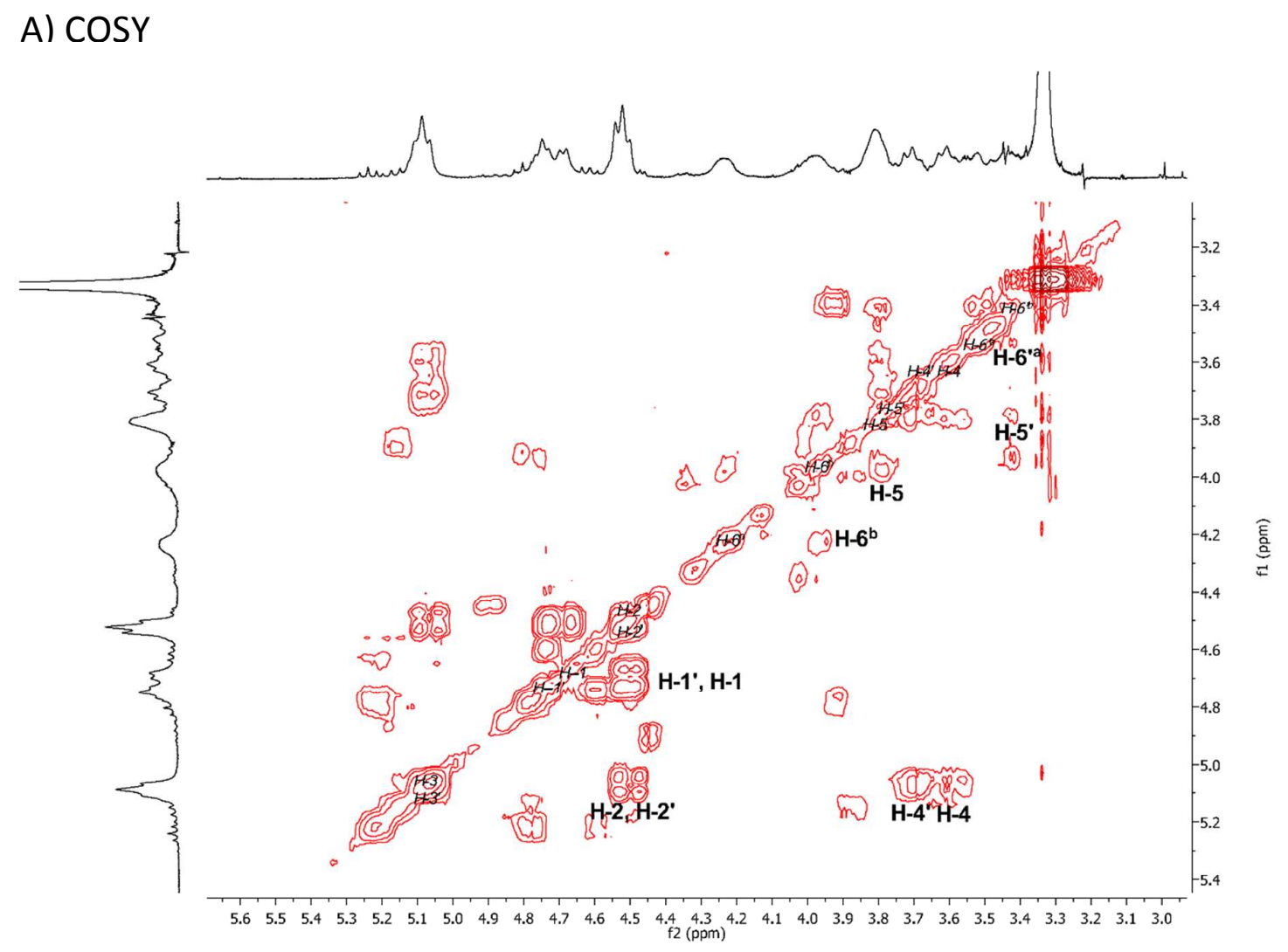

\section{D) TOCSY}

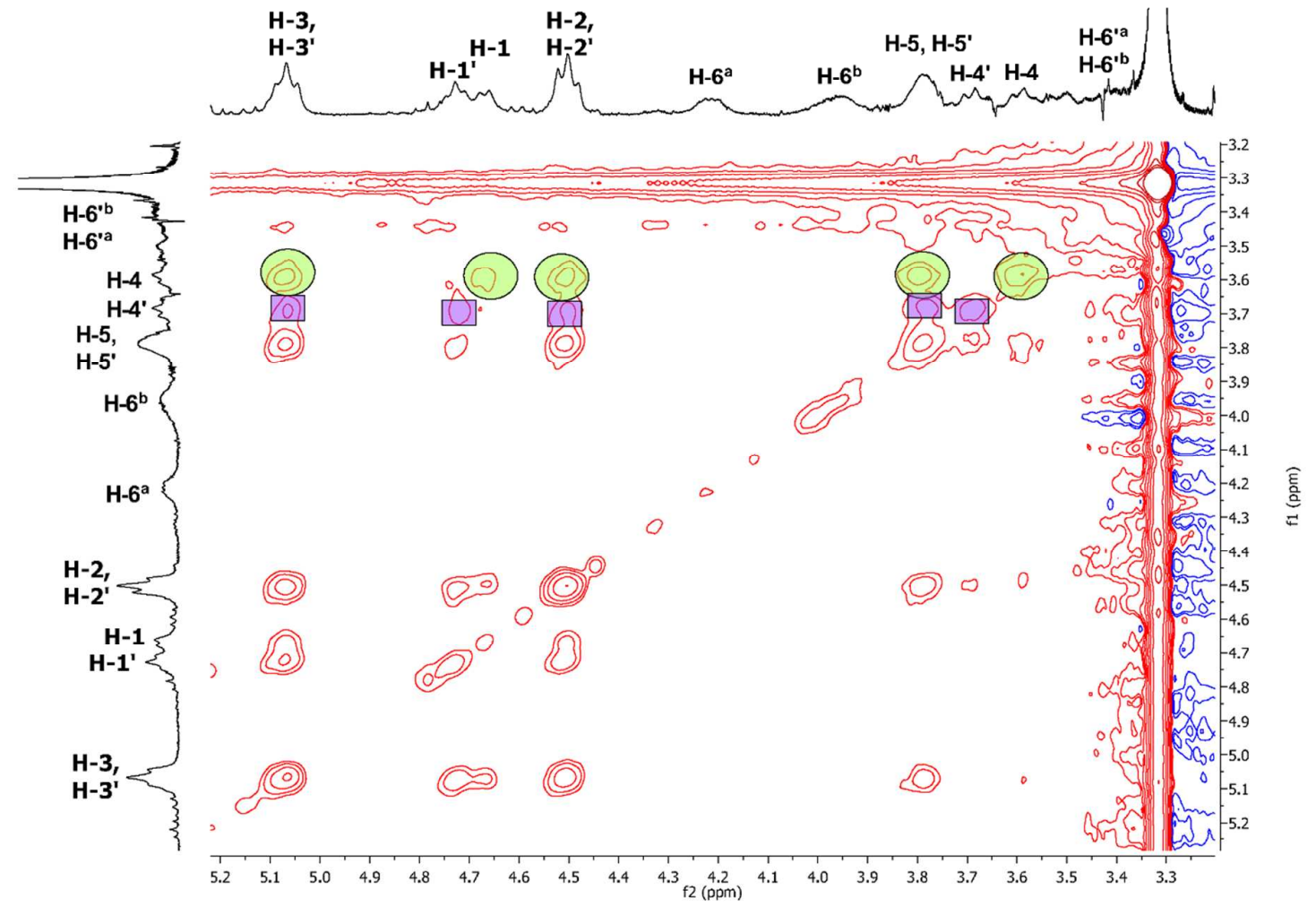




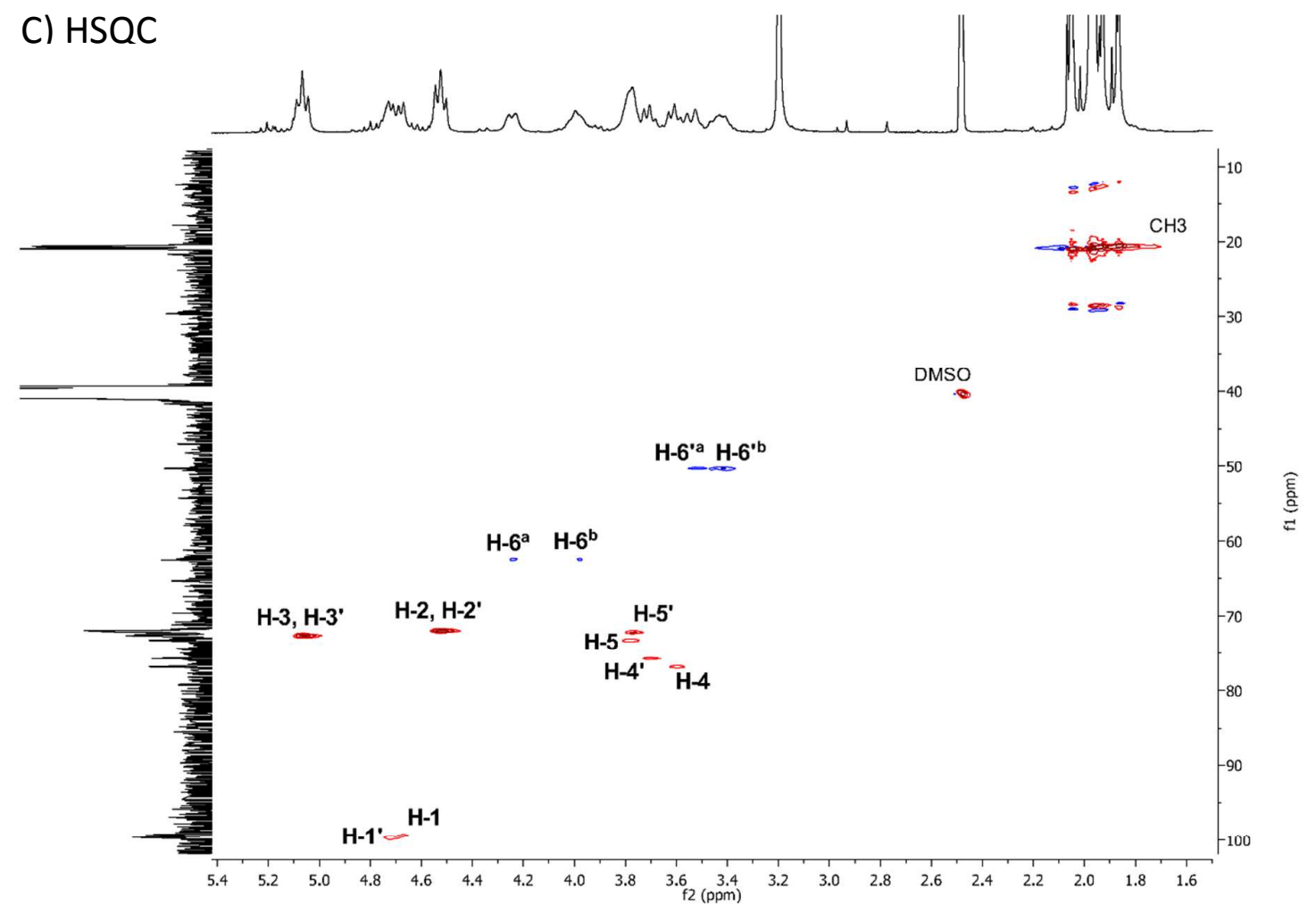


Figure S3. ${ }^{1} \mathrm{H}$-NMR spectrum of acetylated alternating 6-azido-6-deoxycellulose (7)

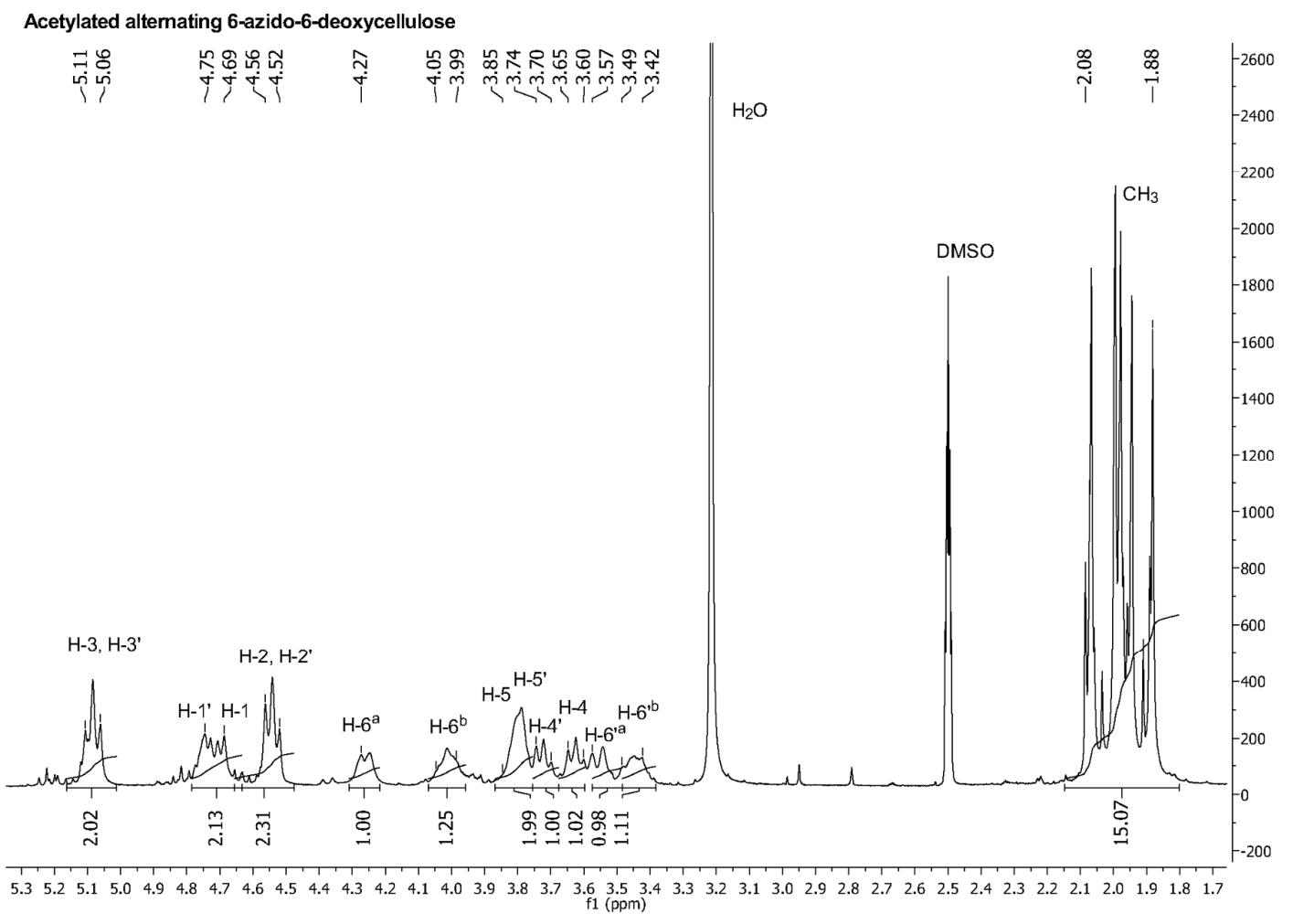

${ }^{1} \mathrm{H}$ NMR (DMSO, $\left.400 \mathrm{MHz}\right) \delta$ 5.11-5.06 (m, 2H, H-3, H-3'), $4.73\left(\mathrm{~d}, 1 \mathrm{H}, \mathrm{H}-1^{\prime}\right), 4.54(\mathrm{~d}, 1 \mathrm{H}, \mathrm{H}-$ 1), 4.56-4.52 (m, 2H, H-2, H-2'), 4.24 (d, 1H, J6a,6b = $11.1 \mathrm{~Hz}, \mathrm{H}-6 \mathrm{a}), 4.05-3.99$ (m, 1H, H-6b), 3.83-3.74 (m, 2H, H-5, H-5'), 3.74-3.70 (m, 1H, H-4'), 3.65-3.60 (m, 1H, H-4), $3.54(\mathrm{~d}, 1 \mathrm{H}$, $\left.J 6^{\prime} a, 6^{\prime} b=12 \mathrm{~Hz}, \mathrm{H}-6^{\prime} a\right)$, 3.49-3.39 (m, 1H, H-6’b), 2.07-1.86 (m, 15H, $\left.\mathrm{CH}_{3}\right)$. 
Figure S4. ${ }^{13} \mathrm{C}$-NMR spectrum of acetylated alternating 6-azido-6-deoxycellulose (7)

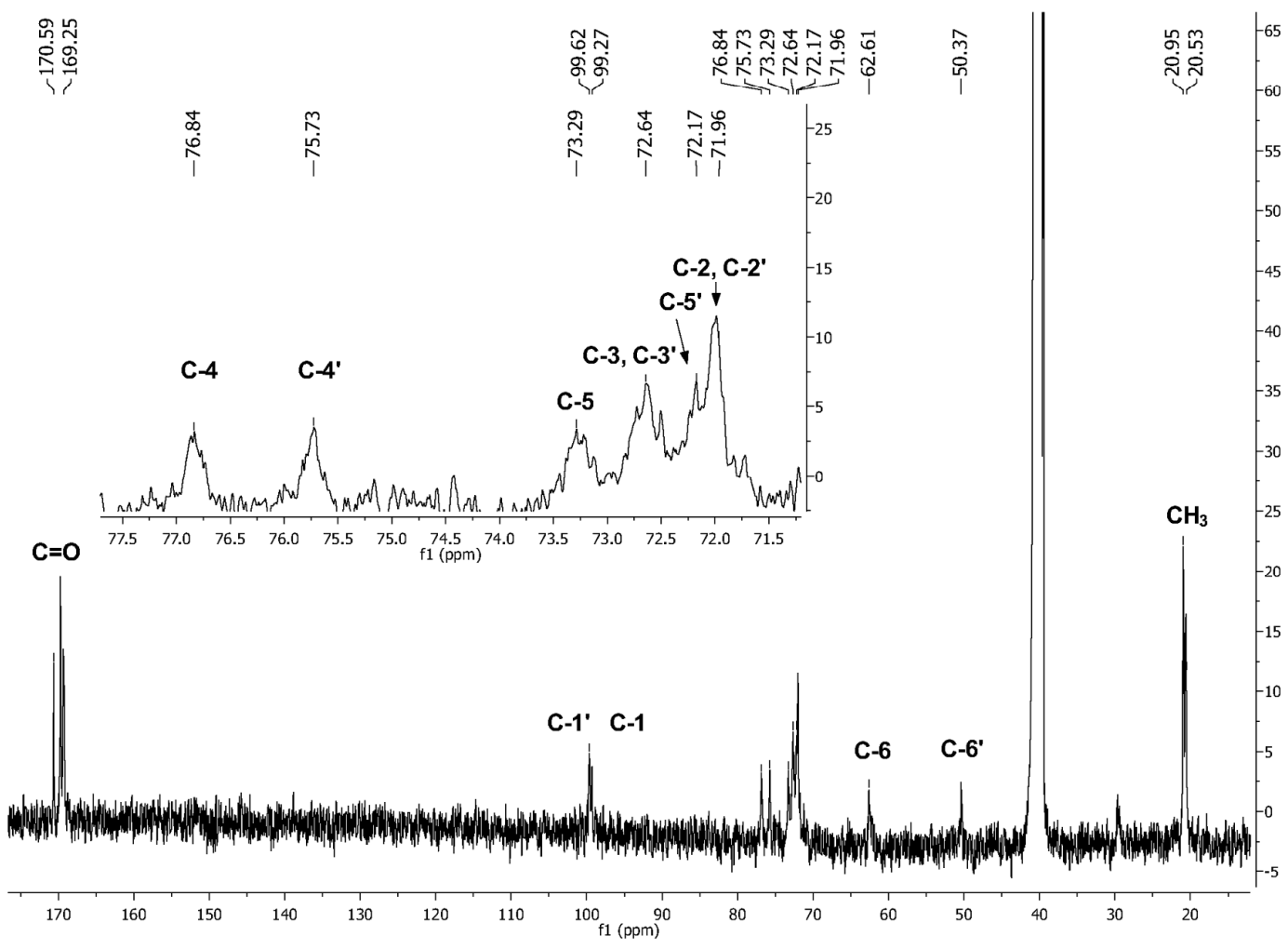

${ }^{13} \mathrm{C}$ NMR (DMSO, $100 \mathrm{MHz}$ ) $\delta 170.59$ - 169.25 (C=0), 99.62 (C-1'), 99.27 (C-1), 76.84 (C-4), 75.73 (C-4'), 73.29 (C-5), 72.64 (C-3, C-3'), 72.17 (C-5'), 71.96 (C-2, C-2'), 62.61 (C-6), 50.37 $\left(\mathrm{C}-6^{\prime}\right), 20.95-20.53\left(\mathrm{CH}_{3}\right)$. 